$39 \%, 34 \%, 27 \%, 9 \%$ and $62 \%$ respectively. There were 256 , 343 cases of employment injury reported in the social security database within the study period. Initial analysis indicated employment injury to be associated with body mass index and metabolic syndrome.

Discussion Non-communicable diseases are now deemed to be an important threat to employees and businesses alike. The findings of this study is important in building the business case for workplace health promotion activities, as health of the employees may directly affect their safety and health performance, and therefore the performance of the businesses.

\section{FACTORS ASSOCIATED WITH BLOOD EXPOSURE ACCIDENTS IN PUBLIC HOSPITALS IN LUBUMBASHI IN DR CONGO}

${ }^{1,2} \mathrm{KF}$ Malonga, 'LH Mbutshu. 'School of Public Health of the University of Lubumbashi, RD Congo; ${ }^{2}$ Faculty of Medicine at the University of Lubumbashi, RD Congo

\subsection{6/oemed-2018-ICOHabstracts.53}

Introduction We conducted a study objectives were to determine the prevalence, profile and factors associated with blood exposure accidents in public hospitals in Lubumbashi.

Methods It was a descriptive analytical study of 112 referred to clinical staff and para-clinical in six public hospitals in Lubumbashi to April 2017. These data were collected in one day in a staff structure in meeting the various services the day of the survey. They were analysed in Epi-Info Version 7 software.

Results Sur personal 112 respondents, 63.4\% were nurses, laboratory technicians $13.4 \%, 12.5 \%$ general practitioners, $5.4 \%$ surface of technicians and specialists $5.4 \%$. The prevalence of blood exposure accidents (AES) was $73.2 \%$. These accidents occurred in the halls of care $(45.5 \%)$, while in custody $(40.0 \%)$ and in the intramuscular and intravenous injections (59.2\%).

The accident pitting (74.4\%) were the most frequent type and associated factors were the act of suturing wounds (3.4; CI $=[1.1$ to 10.9]), the injection instrument (36.2, CI: 4.4 to 297,3 ).

Nursing (14.7; CI: 1.6 to 134.6) and the lab technician were more likely than others (13.8, CI: 1.2 to 156.7$)$.

Conclusion The prevalence of blood exposure accidents is high; it concerns nurses and laboratory technicians in the public hospitals of Lubumbashi.

It is important to sensitising them to compliance with standard precautions for the fight against such accidents.

\section{8 'WHAT YOU CANNOT MEASURE, YOU CANNOT DELIVER'; TRACING CORRELATION BETWEEN OSH DATA CAPTURE AND HSE PERFORMANCE AT SELECTED WORKPLACES (UGANDA)}

\footnotetext{
1,2,3Eva Katusabe. 'Department Of Occupational Safety, Kampala, Uganda; '2Uganda Institution of Professional Engineers, Kampal Uganda; 3 International Commission on Occupational Health, Kampala, Uganda
}

\subsection{6/oemed-2018-ICOHabstracts.54}

Introduction Uganda's 38.3 million population and 17.2 million labour-force are on the rise, creating high pressure of job creation and a working populace that's ready to settle for 'any job' which often implies compromising their safety and health. Government programs geared towards compelling employers to institute safety measures for decent and social economic development, can only be effectively designed starting with clear picture of the extent of the problem, and statistical evidence of the gaps/issues for redress.

Methods Using case studies of randomly selected workplaces from different sectors of Uganda's economy, scrutiny was done of the available statistics as well as the retrospective evaluation of the underlying challenges hindering effective data collection in the country. Stakeholder analysis was undertaken to identify the various parties that have a role to play in data collection, their achievements and challenges faced.

Results Uganda's labour-force varies in numbers and gender distribution per sector; Agriculture employs 74\% (11.6 million, 46\% male), Trade, Leisure and hospitality employs $9.4 \%$ (1.5 million, 46\% male), manufacturing employs $4.9 \%$ (780,000, 55\% male), Public Sector employs 4.5\% (716,000, $51 \%$ male), $2 \%$ in transport and communication (98\% male), $1.7 \%$ in construction ( $97 \%$ male), and $3.5 \%$ engaged in mining/quarrying, finance, energy, etc.

Literacy rate of adult population (over 15 years) is $73.87 \% ; 80.85 \%$ and $66.89 \%$ for males and females respectively. Youth (15-24 years) literacy rates are $87.43 \%$ and $86.57 \%$ for males and females respectively. These Ugandans continue to suffer occupational illnesses, injuries and fatalities, which aren't documented in absence of effective data capture systems.

Discussion The study attempts to draw linkages between workplaces that attempt to capture $\mathrm{OSH}$ data with their general HSE performance, building the case of the need to collect this information so as to feed into national data bases hence inform policy decisions for improved HSE performance and building a safety culture.

\section{AGRICULTURAL MACHINE-RELATED INJURIES IN SOUTH KOREA}

K Kim*, D Choi, K Lee, H Chae, H Lee, W Choi. National Academy of Agricultural Science, Rural Development Administration, Jeonju, Republic of Korea

\subsection{6/oemed-2018-ICOHabstracts.55}

Introduction Along with a growth of machinery use and ageing population in Korean farms, risk of agricultural machinerelated injury has been increasing. Agricultural machines have been reported as the main cause materials for agricultural injuries across many countries. The aim of this study is to examine risk and patterns of occupational machine-related injury among farmers in Korea.

Methods This study analysed data from the South Korea Farmers' Occupational Disease and Injury Survey that was conducted in 2015 by the Rural Development Administration, South Korea. Farm samples across all provinces were chosen by a multistage stratified method to represent the whole farms in South Korea. Survey was conducted through trained farmvisiting interviewers. The experience of occupational injury occurred in 2014 was surveyed, and the incidence rate of injury were calculated.

Results A total of 15654 farmers over the age of 19 (9,983 farm families) were surveyed. Agricultural machine-related injury accounted for $33.2 \%$ of all agricultural occupational injuries that need convalescence of one day and more due to the injury. The rate of occupational agricultural machinerelated injury was 1.15 per 100 person-years among farmers who used agricultural machines. Injury rates were higher for males (1.18) than females, and consistently increased with age. 
The three top injury-leading agricultural machines were Gyeong-ungi, tractor, and bush cutter.

Conclusion Agricultural machines were the main cause of occupational injuries for Korean farmers. Priority for prevention efforts should be given to more vulnerable populations (i. e., older males). For effective prevention, comprehensive strategies that incorporate engineering safety and improvement of agricultural working environment (e.g., farm road) as well as safety training and education are needed.

Funding Rural Development Administration, Republic of Korea (Project No. PJ 01001705).

\section{COMMUNITY-BASED FARM SAFETY INTERVENTION IN SOUTH KOREA}

K Kim*, D Choi, H Chae, H Kim, K Kim, K Lee. National Academy of Agricultural Science, Rural Development Administration, Jeonju, Republic of Korea

\subsection{6/oemed-2018-ICOHabstracts.56}

Introduction Intervention strategies to reduce agricultural injuries for self-employed farmers have been sought and evaluated in many prior studies. The aim of this study is to introduce the characteristics and effects of several types of farm safety interventions in South Korea.

Methods This study reviewed reports and documents of community-based farm safety interventions conducted by Korean central government through RDA (Rural Development Administration). The frameworks, main contents, effects, and implications of the intervention programs were described.

Results Since 2006, three main community-based farm safety intervention programs have been conducted by RDA, which were 'Farm Safety Model (2006-2015,133 farm villages)', 'Supporting Program of Farming Convenient Equipment (2008-2017, 1484 farm villages)', and 'Customised Farm safety Management Program (2015 current, 230 farmer’s cooperative units in 2015)'.

- 'Farm Safety Model' where professionals facilitated various interventions including farm safety education, an evaluation of risk factors on farm worksites, and health examination were apprised as effective in enhancing safety consciousness and safety management capacity of farmers.

- 'Supporting Program of Farming Convenient Equipment' was proved to reduce symptoms of musculoskeletal disorders among farmers participated.

- 'Customised Farm safety Management Program' that consisted of safety education, evaluation of risk factors on farm worksites, and customised supporting for occupational health and safety was evaluated as effective in enhancing the level of safety management on farming environment and hazards.

Conclusion Based on experiences from the existing intervention programs, the following are recommended for future strategies for agricultural health and safety: the main stream of community-based interventions is better to be farmers or farm leaders; intervention programs are recommended to contain both safety education/training and working environment interventions at least; national training programs and system for farm safety managers and farm leaders are needed.

Funding Rural Development Administration, Republic of Korea (Project No. PJ01250905).

\section{HYDROFLUORIC ACID: UPDATE ABOUT KNOWLEDGE ON EYE/SKIN AND RESPIRATORY EXPOSURE DAMAGES} AND DECONTAMINATION

${ }^{1}$ Laurence Mathieu*, ${ }^{1}$ François Burgher, ${ }^{2}$ Samuel Constant, ${ }^{2}$ Song Huang, ${ }^{3}$ Alan H Hall, ${ }^{1}$ Joël Blomet, ${ }^{4}$ Jean-Luc Fortin, ${ }^{5}$ NF Schrage. ${ }^{1}$ Prevor Laboratory Moulin de Verville 95760 Valmondois, France; '2Epithelix Sarl 14 Chemin des Aulx - CH-1228 Plan-les-Ouates, Geneva, Switzerland; ${ }^{3}$ Medical Toxicologist Toxicology Consulting and Medical Translating Services Springtown and Azle, Texas USA and Clinical Assistant Professor, Colorado School of Public Health, University of Colorado-Denver, Denver, Colorado, USA; ${ }^{4}$ Unité de médecine préventive -Ville de Saint-Etienne, 82 boulevard Bergson -42 000 Saint-Etienne; Centre des brûlés, Hôpital St-Luc-St-Joseph, 20 quai Cl. Bernard, 69365 Lyon Cedex 07; Service des Urgences, Hôpital d'Instruction des Armées de Desgenettes, 69000 Lyon; CAPTV, Hospices Civils de Lyon, 126 Boulevard Lacassagne, 69424 Lyon cedex 03; ${ }^{5}$ Augenklinik Köln Merheim; Acto Aachen, Germany

\subsection{6/oemed-2018-ICOHabstracts.57}

Introduction Hydrofluoric acid (HF) is very corrosive and toxic for humans by all routes of exposures.

Materials and methods Recent ex vivo studies have been conducted on eye, skin and respiratory track in order to determine the damages induced by HF. For respiratory effects, an experiment was designed to explore HF toxicological doses and effects on MucilAir ${ }^{\mathrm{m}}$, a unique 3D Human Airway Epithelia reconstructed in vitro. Review of current available literature on clinical data was also performed.

Results For inhalation exposure, up to $1.5 \mathrm{mM} \mathrm{HF}$, no toxic effect was detected. From $7.5 \mathrm{mM}$, damage to epithelia were observed but could be repaired 7 days after exposure. $75 \mathrm{mM}$ HF and above caused severe non reversible damage to epithelia. Ex Vivo Eye Irritation Test (EVEIT) combined with OCT allowed to characterise HF ocular burn with a complete diffusion into the cornea within $240 \mathrm{~s}$ for a $2.5 \%$ concentration. Ex Vivo study on human skin explants showed a diffusion in full skin within 5 min after a 70\% HF exposure. Decontamination on both eye/skin ex vivo models with water alone or with calcium gluconate limited the diffusion but did not prevent all damages, whereas decontamination with an hypertonic amphoteric exposure such Hexafluorine solution avoided the diffusion and damages. This result is in agreement with the analysis of the clinical results of the literature.

Conclusion Experimental models can help to understand chemical damages from HF exposures and design management based on new tools and devices in order to provide immediate and efficient decontamination to protect exposed workers.

\section{OBSTRUCTIVE SLEEP APNEA SYNDROME AND FITNESS TO DRIVE OF COMMERCIAL MOTOR VEHICLE DRIVERS - STATE-OF-THE-ART REVIEW}

WLC Van Hooste*. MD, Mediwet Occupational Health Services, External Service for Prevention and Protection at Work, Ghent, Belgium

\subsection{6/oemed-2018-ICOHabstracts.58}

Introduction Obstructive Sleep Apnea Syndrome (OSAS) is a very common disease with potentially severe health and social consequences. Untreated OSAS is associated with increased risk of motor vehicle accidents, caused by excessive daytime sleepiness (EDS). Sleepiness at the wheel is the cause of accident in 5 tot $7 \%$ of the cases. The overall risk of accidents for OSAS patients is elevated by a factor 2.4 to 3.7. OSAS is more common among commercial motor vehicle (CMV) drivers, due to obesitas for example. 